\title{
Physical Activity and Survival after Diagnosis of Invasive Breast Cancer
}

\section{Citation}

Holick, C. N., P. A. Newcomb, A. Trentham-Dietz, L. Titus-Ernstoff, A. J. Bersch, M. J. Stampfer, J. A. Baron, K. M. Egan, and W. C. Willett. 2008. "Physical Activity and Survival after Diagnosis of Invasive Breast Cancer." Cancer Epidemiology Biomarkers \& Prevention 17 (2): 379-86. https:// doi.org/10.1158/1055-9965.epi-07-0771.

\section{Permanent link}

http://nrs.harvard.edu/urn-3:HUL.InstRepos:41292867

\section{Terms of Use}

This article was downloaded from Harvard University's DASH repository, WARNING: This file should NOT have been available for downloading from Harvard University's DASH repository.

\section{Share Your Story}

The Harvard community has made this article openly available.

Please share how this access benefits you. Submit a story. 


\title{
Physical Activity and Survival after Diagnosis of Invasive Breast Cancer
}

\author{
Crystal N. Holick, ${ }^{1}$ Polly A. Newcomb, ${ }^{1}$ Amy Trentham-Dietz, ${ }^{2,3}$ Linda Titus-Ernstoff,,${ }^{4,5}$ \\ Andrew J. Bersch, ${ }^{2}$ Meir J. Stampfer, ${ }^{7,8}$ John A. Baron, ${ }^{4,6}$ Kathleen M. Egan, ${ }^{9}$ \\ and Walter C. Willett 7,8 \\ ${ }^{1}$ Cancer Prevention Program, Fred Hutchinson Cancer Research Center, Seattle, Washington; ${ }^{2}$ Paul P. Carbone Comprehensive Cancer \\ Center and ${ }^{3}$ Department of Population Health Sciences, University of Wisconsin, Madison, Wisconsin; ${ }^{4}$ Department of Community \\ and Family Medicine and Norris Cotton Cancer Center, ${ }^{5}$ Department of Pediatrics, and ${ }^{6}$ Department of Medicine, Dartmouth \\ Medical School, Lebanon, New Hampshire; 'Channing Laboratory, Department of Medicine, Brigham and Women's Hospital, \\ Harvard Medical School; ' Departments of Epidemiology and Nutrition, Harvard School of Public Health, Boston, \\ Massachusetts; and ${ }^{9}$ Moffitt Cancer Center and Research Institute and University of South Florida, Tampa, Florida
}

\begin{abstract}
Previous studies suggest that increased physical activity may lower the risk of breast cancer incidence, but less is known about whether levels of physical activity after breast cancer diagnosis can influence survival. We prospectively examined the relation between postdiagnosis recreational physical activity and risk of breast cancer death in women who had a previous invasive breast cancer diagnosed between 1988 and 2001 (at ages 20-79 years). All women completed a questionnaire on recent postdiagnosis physical activity and other lifestyle factors. Among 4,482 women without history of recurrence at the time of completing the questionnaire, 109 died from breast cancer within 6 years of enrollment. Physical activity was expressed as metabolic equivalent task-hours per week (MET-h/wk); hazard ratios (HR) and $95 \%$ confidence intervals $(95 \%$ CI) were estimated using Cox proportional hazards regression. After adjusting for age at diagnosis, stage of disease, state of residence, interval between diag-
\end{abstract}

nosis and physical activity assessment, body mass index, menopausal status, hormone therapy use, energy intake, education, family history of breast cancer, and treatment modality compared with women expending <2.8 MET-h/wk in physical activity, women who engaged in greater levels of activity had a significantly lower risk of dying from breast cancer (HR, 0.65; 95\% CI, 0.39-1.08 for 2.8-7.9 MET-h/wk; HR, 0.59; 95\% CI, 0.35-1.01 for 8.0-20.9 MET-h/wk; and HR, 0.51; 95\% CI, 0.29-0.89 for $\geq 21.0 \mathrm{MET}-\mathrm{h} / \mathrm{wk} ; P$ for trend $=0.05$ ). Results were similar for overall survival (HR, 0.44; 95\% CI, $0.32-0.60$ for $\geq 21.0$ versus $<2.8 \mathrm{MET}-\mathrm{h} / \mathrm{wk}$; $P$ for trend $<0.001$ ) and were similar regardless of a woman's age, stage of disease, and body mass index. This study provides support for reduced overall mortality and mortality from breast cancer among women who engage in physical activity after breast cancer diagnosis. (Cancer Epidemiol Biomarkers Prev 2008;17(2):379-86)

\section{Introduction}

At present, $\sim 2$ million U.S. women have a history of breast cancer (1). For this large population of women, factors that influence survival are of critical importance. Even after accounting for stage at diagnosis and treatment, survival varies greatly (2), a finding that suggests an influence of modifiable lifestyle factors, such as physical activity.

Few studies have considered the influence of lifestyle, such as physical activity, on breast cancer-specific survival. Postdiagnosis physical activity has been associated with improved quality of life (3), but few observational studies have examined whether lifestyle may affect survival. A recent prospective study found that women who

\footnotetext{
Received 8/22/07; revised 11/6/07; accepted 11/19/07.

Grant support: The Susan G. Komen Breast Cancer Foundation grant POP0504234 and National Cancer Institute, NIH, Department of Health and Human Services grants CA47147, CA47305, CA69664, and CA94880.

The costs of publication of this article were defrayed in part by the payment of page charges. This article must therefore be hereby marked advertisement in accordance with 18 U.S.C. Section 1734 solely to indicate this fact.

Requests for reprints: Crystal N. Holick, i3 Drug Safety, Suite 3800, 950 Winter Street, Waltham, MA 02451. Phone: 203-417-1466. E-mail: crystal.holick@i3drugsafety.com

Copyright (c) 2008 American Association for Cancer Research.

doi:10.1158/1055-9965.EPI-07-0771
}

engaged in physical activity after a diagnosis of breast cancer had a statistically significant $20 \%$ to $50 \%$ lower risk of death from breast cancer (4). Hormonal changes induced during exercise, such as lower blood estrogen $(5,6)$ or insulin growth factor-I $(7,8)$ concentrations, or lower levels of adiposity (9) may explain the relationship between physical activity and survival among breast cancer survivors.

There is an urgent need for information on factors contributing to long-term survival given the advancements of early detection and treatment modalities (10). To determine whether postdiagnosis physical activity is associated with survival among women with a breast cancer diagnosis, we analyzed data from a large cohort of breast cancer survivors enrolled in the Collaborative Women's Longevity Study (CWLS), a population-based prospective study established to examine the contribution of lifestyle to longevity in women with breast cancer.

\section{Materials and Methods}

Study Participants. The CWLS is a cohort of women, ages 20 to 79 years at breast cancer diagnosis, who were 
recruited after their participation as cases in a population-based case-control study of breast cancer conducted in Wisconsin, Massachusetts (excluding metropolitan Boston), and New Hampshire between 1988 and 2001 (11-13). The primary objective of the CWLS is to evaluate a series of hypotheses regarding the association of survival with modifiable lifestyle factors, such as diet and physical activity, after breast cancer diagnosis. In the parent case-control study, women with a recent diagnosis of invasive breast cancer completed a standardized telephone interview $(n=18,273)$ within 2 years of diagnosis. The interview included questions regarding prediagnostic information on established and emerging risk factors for breast cancer, including physical activity. In addition, screening history, tumor staging, and histology [from state cancer registries (14)] and treatment (selfreported and from state cancer registries) information were available. Overall participation rates exceeded $80 \%$ among eligible women in the parent case-control study $(11,15)$. This study was approved by the institutional review boards at both the Harvard School of Public Health and the University of Wisconsin.

From 1998 to 2001, surviving cases were asked to participate in the CWLS by completing a mailed questionnaire. The CWLS questionnaire assessed recent (within the past year) postdiagnosis physical activity, diet, weight gain, medication history, alternative therapies, quality of life, and other lifestyle factors. Participants who did not return the questionnaire received a reminder telephone call and a second mailing 3 weeks after the initial mailing to enhance response. Of the 18,273 women eligible, a total of 5,803 (32\%) women ultimately completed the CWLS questionnaire. Among the remaining 12,470 women enrolled in the parent casecontrol study who did not complete the questionnaire, 2,663 had died before January 1, 1999. An additional 989 could not be located. For purposes of the current analysis, we excluded women with missing information on postdiagnosis physical activity, with distant metastases or unknown stage of breast cancer at diagnosis, and who reported any recurrence of breast cancer after the initial diagnosis. When compared with CWLS participants, nonparticipants were more likely to have regional involvement of their breast cancer, to be current smokers at diagnosis, and were less likely to have a high school education (Table 1).

Recreational Physical Activity Assessment. Information collected on recreational physical activity in the CWLS questionnaire was modeled after data collection instruments used in a previous cohort study (4); the validity of the physical activity assessment has been reported previously (16). Women reported the average time per week spent participating in each of six recreational activities over the previous year: walking outdoors; running ( $\geq 10 \mathrm{~min} / \mathrm{mile})$; lap swimming; tennis, squash, or racquetball; calisthenics, aerobics, or rowing machine; and other aerobic recreation (e.g., lawn mowing). Ten response categories were possible ranging from 0 to $11+\mathrm{h} / \mathrm{wk}$. Participants also reported their usual walking pace (easy or $<2 \mathrm{mph}$, average or 2-2.9 $\mathrm{mph}$, brisk or 3-3.9 mph, and very brisk or $\geq 4 \mathrm{mph}$ ) and the number of flights of stairs climbed daily.

Each activity was assigned a metabolic equivalent task (MET) score (17). MET scores for specific activities are defined as the ratio of the metabolic rate associated with each activity divided by the resting metabolic rate. The reported time spent at each activity per week was multiplied by its typical energy expenditure requirements to derive a MET-hours per week (MET-h/wk) total recreational physical activity score. One MET-h is the amount of energy expended when sitting quietly for $1 \mathrm{~h}$ and is equivalent to $3.5 \mathrm{~mL}$ of oxygen uptake per kilogram of body weight per minute. Three MET-h is equivalent to walking at average pace of 2 to $2.9 \mathrm{mph}$ for $1 \mathrm{~h}$. In accordance with the Centers for Disease Control and Prevention and the American College of Sports Medicine guidelines (18), total recreational physical activity was further classified as moderate intensity (activities that expend $<6 \mathrm{MET}$, including walking outdoors and stair climbing) or vigorous intensity (activities that expend $\geq 6$ MET, including the other specified activities). If a participant provided a response to at least one of the activities, the activities without responses were assumed to be zero.

Outcome Assessment. We assessed all breast cancer cases for mortality regardless of whether they completed the CWLS questionnaire. We matched cases through linkage to the National Death Index records to obtain date and underlying cause of death, which has been shown to be a reliable source $(19,20)$.

Statistical Analysis. Person-time of follow-up was calculated from the date of return of the CWLS follow-up questionnaire (1998-2001) until the date of death or the end of follow-up (December 31, 2004), whichever came first. Among women who completed the CWLS questionnaire $(n=5,803)$, we excluded women who had missing information on physical activity $(n=136)$ and women with distant metastases $(n=35)$ or unknown disease stage at diagnosis $(n=615)$. We also excluded women who reported any recurrence of breast cancer after the initial diagnosis and before entry into the CWLS $(n=535)$. The final cohort for analysis included 4,482 women. Women were followed for a maximum of 6 years after returning the questionnaire (mean $\pm S D$, $5.5 \pm 1.1$ years). After exclusions, there were 412 deaths, 109 from breast cancer.

We created quartiles of MET-h/wk of total and of moderate-intensity recreational physical activity based on the total distribution of physical activity in the entire cohort. Because $50 \%$ of the cohort did not participate in any vigorous-intensity physical activity, we defined the reference category for vigorous-intensity physical activity as 0.0 MET-h/wk of vigorous-intensity activity with the remainder of the cohort divided into tertiles of MET-h/wk. Cox proportional hazards models were used to estimate the hazard ratio (HR) and $95 \%$ confidence interval $(95 \% \mathrm{CI})$ for breast cancer death (or death from any cause) according to physical activity levels and to adjust simultaneously for potential risk factors associated with breast cancer survival. Data on potential breast cancer risk factors were available from the parent casecontrol study and the CWLS.

However, some factors (e.g., stage of disease and treatment modality) were only collected in the parent case-control study. Multivariable models included terms for age at diagnosis (5 years), stage of disease at diagnosis (local or regional), state of residence at diagnosis (Massachusetts, New Hampshire, and Wisconsin), time 
Table 1. Selected characteristics of participants and nonparticipants in the CWLS

\begin{tabular}{|c|c|c|}
\hline Characteristics at diagnosis* & CWLS participants $^{\dagger}(n=4,482)$ & CWLS nonparticipants $^{\ddagger}(n=7,786)$ \\
\hline Mean age at diagnosis (y) & 58.5 & 59.4 \\
\hline \multicolumn{3}{|c|}{ Breast cancer stage at diagnosis $(\%)$} \\
\hline Local & 72.6 & 70.0 \\
\hline Regional & 27.4 & 30.0 \\
\hline Mean age at menarche $(y)$ & 12.7 & 12.8 \\
\hline Mean age at first live birth (y) & 24.4 & 24.3 \\
\hline Parity, mean & 2.7 & 2.6 \\
\hline Postmenopausal (\%) & 72.7 & 72.3 \\
\hline Education, $\geq 12$ y (\%) & 91.4 & 82.9 \\
\hline BMI $\left(\mathrm{kg} / \mathrm{m}^{2}\right)$, mean & 25.6 & 26.1 \\
\hline \multicolumn{3}{|c|}{ Early-life vigorous-intensity recreational physical activity ${ }^{\S}(\%)$} \\
\hline None & 52.1 & 53.8 \\
\hline Low & 26.4 & 23.1 \\
\hline High & 20.5 & 20.9 \\
\hline \multicolumn{3}{|l|}{ Smoking history (\%) } \\
\hline Never & 48.2 & 48.7 \\
\hline Former & 34.5 & 28.8 \\
\hline Current & 17.0 & 21.3 \\
\hline Alcohol (drinks daily), mean & 3.3 & 3.1 \\
\hline
\end{tabular}

*Data obtained in parent case-control studies.

†Excludes women with missing information on postdiagnosis physical activity $(n=136)$, distant metastases $(n=35)$ or unknown $(n=615)$ stage breast cancer at diagnosis, and any recurrence of breast cancer $(n=535)$.

$\ddagger$ Excludes women with distant metastases $(n=134)$ or unknown $(n=898)$ stage breast cancer at diagnosis, who died before January $1,1999(n=2,663)$, and who did not receive the CWLS questionnaire $(n=989)$.

$\S$ Defined as participation in vigorous-intensity physical activities, such as running; jogging; bicycling, including stationary; calisthenics, aerobics, aerobic dance, and rowing machine; and tennis.

interval between breast cancer diagnosis and assessment of physical activity, postdiagnosis body mass index (BMI; $<24.9,25.0-29.9, \geq 30.0 \mathrm{~kg} / \mathrm{m}^{2}$ ), postdiagnosis menopausal status, postdiagnosis hormone therapy use (never, former, current), total energy intake the year before enrollment in the CWLS (quintiles; kcal), education level at diagnosis $(<12, \geq 12$ years), first-degree family history of breast cancer at diagnosis, and initial treatment modality (radiation, chemotherapy, tamoxifen). In models assessing moderate-intensity recreational physical activity, we further adjusted for vigorous-intensity recreational activity and vice versa.

We also considered potential confounding by postdiagnosis smoking history (never, former, current), alcohol consumption the year before enrollment in the CWLS (nondrinker, $\leq 1,>1$ drink a day), and prediagnostic recreational physical activity. Physical activity before diagnosis was available from the parent case-control study and varied by period $(13,21)$. All women provided information on vigorous-intensity physical activity between ages 12 and 22 years. From 1992 to 1995, women provided information on recent (within 5 years of breast cancer diagnosis) total recreational physical activity; from 1997 to 2001, women provided information on lifetime vigorous-intensity recreational physical activity.

To minimize the possible influence of possible occult recurrent disease on total recreational physical activity, we did a subgroup analysis excluding women who died within 1 and 2 years of completing the CWLS survey. Additional models were restricted to women who reported no recent unintentional weight loss $(\geq 5 \%$ of body weight) or women with a mammogram or physician breast exam after their diagnosis. We considered whether the influence of physical activity (median, 8.0 MET-h/wk) on breast cancer survival varied according to age at breast cancer diagnosis (median, 59 years old), tumor stage at diagnosis (local and regional), and postdiagnosis BMI $\left(<25\right.$ and $\left.\geq 25 \mathrm{~kg} / \mathrm{m}^{2}\right)$ and menopausal status. We also evaluated whether physical activity associations varied by time since breast cancer diagnosis. These and other tests for (multiplicative) interaction were assessed by examining stratum-specific estimates and by use of likelihood ratio tests. The validity of the proportional hazards assumption was assessed using interaction terms of survival time by physical activity, and likelihood ratio tests showed no evidence for departure from this assumption. Tests of linear trend were conducted by assigning the median values for each category of physical activity (including the reference category) and treating those as a single continuous variable. The Kaplan-Meier (product-limit) method was used to generate survival probability curves (22). All reported $P$ values are two tailed, and statistical significance was evaluated at 0.05 . All analyses were done using SAS version 9.1 (SAS Institute).

\section{Results}

A total of 4,482 eligible women completed the CWLS questionnaire a median of 5.6 years after their breast cancer diagnosis. Fewer than $10 \%$ of women were enrolled in the CWLS cohort within 2 years of diagnosis; $57 \%$ had survived $\geq 5$ years before enrolling into the study and $13 \%$ for $\geq 10$ years.

At diagnosis, women who were more physically active were diagnosed at a younger age, with localized breast cancer, and more likely to be a high school or college graduate than did women with lower levels of postdiagnosis exercise (Table 2). At follow-up, the majority of women were postmenopausal and obese, and current smokers were less likely to participate in postdiagnosis recreational physical activity. Compared with women with lower levels of postdiagnosis exercise, women who 
Table 2. Selected characteristics of women with breast cancer in the CWLS by total postdiagnosis recreational physical activity category

\begin{tabular}{|c|c|c|c|c|}
\hline \multirow[t]{2}{*}{ Characteristics } & \multicolumn{4}{|c|}{ Total recreational physical activity after diagnosis (MET-h/wk) } \\
\hline & $\leq 2.7(n=1,105)$ & $2.8-7.9(n=1,072)$ & $8.0-20.9(n=1,184)$ & $\geq 21.0(n=1,121)$ \\
\hline \multicolumn{5}{|l|}{ Characteristics at diagnosis* } \\
\hline Mean age at diagnosis $(y)$ & 61.7 & 58.7 & 57.3 & 56.4 \\
\hline Ethnicity (\% Caucasian) & 98.6 & 99.0 & 98.7 & 98.3 \\
\hline \multicolumn{5}{|l|}{ Breast cancer stage at diagnosis (\%) } \\
\hline Local & 74.2 & 73.7 & 72.3 & 60.4 \\
\hline Regional & 25.8 & 26.3 & 27.7 & 29.6 \\
\hline First-degree family history of breast cancer (\%) & 20.2 & 18.2 & 22.5 & 19.0 \\
\hline Education, $\geq 12$ y (\%) & 86.1 & 91.2 & 94.2 & 93.9 \\
\hline \multicolumn{5}{|l|}{ Characteristics at follow-up ${ }^{\dagger}$} \\
\hline Postmenopausal (\%) & 91.2 & 84.2 & 81.7 & 78.4 \\
\hline BMI $\left(\mathrm{kg} / \mathrm{m}^{2}\right)$, mean & 28.7 & 27.5 & 26.5 & 25.7 \\
\hline Smoking history (\% current) & 12.9 & 10.5 & 7.0 & 9.2 \\
\hline Alcohol (drinks daily), mean & 0.4 & 0.4 & 0.4 & 0.5 \\
\hline Energy intake $^{\ddagger}(\mathrm{kcal} / \mathrm{d})$, mean & 1,646 & 1,711 & 1,739 & 1,760 \\
\hline Hormone therapy (\% current) & 1.5 & 2.1 & 2.7 & 2.8 \\
\hline
\end{tabular}

*Data obtained in parent case-control studies.

tData obtained in CWLS questionnaire.

$\ddagger$ Year before enrollment in CWLS.

were more physically active were more likely to consume alcohol or use hormone therapy currently at follow-up than did women with lower levels of postdiagnosis exercise. Other characteristics, including first-degree family history of breast cancer and total energy intake the year before enrollment in the CWLS, did not vary substantially by category of postdiagnosis activity.

Overall, we observed a significantly lower risk of death from breast cancer and death from any cause with increasing total postdiagnosis recreational physical activity (Table 3). Analyses in which postdiagnosis recreational physical activity was classified as moderate or vigorous intensity showed that women who participated in moderate-intensity activity had a lower risk of death. However, there was no association of vigorous-intensity recreational physical activity and risk of breast cancer death. An increment of 5 MET-h/wk of moderate-intensity activity was associated with $15 \%$ lower risk of breast cancer death (HR, 0.85; 95\% CI, 0.74-0.98; $P$ for linear trend $=0.03$ ); an increment of $5 \mathrm{MET}-\mathrm{h} / \mathrm{wk}$ of vigorous-intensity activity was not associated with a decrease in risk of breast cancer death $(\mathrm{HR}, 1.01 ; 95 \% \mathrm{CI}, 0.90-1.12 ; P$ for linear trend $=0.92)$. Similar associations with recreational physical activity were observed for risk of death from any cause. All associations were essentially unchanged after adjustment for potential confounders (Table 3), including postdiagnosis smoking history and alcohol consumption the year before enrollment in the CWLS.

Adjustment for early-life (ages 12-22 years) vigorousintensity physical activity before diagnosis also did not change the associations with recreational physical activity observed in Table 3 (data not shown). Similarly, adjustment for either most recent (within 5 years of diagnosis) total recreational physical activity before diagnosis (asked 1992-1995 at baseline; $n=1,613$ ) or lifetime vigorous-intensity recreational physical activity before diagnosis (asked 1997-2001 at baseline; $n=1,653$ ) did not materially change the associations shown in Table 3 (data not shown).

All results were essentially unchanged after excluding women who had died within 1 year of completing the
CWLS questionnaire ( $n=30$; Table 3$)$; similar associations were also observed after excluding women who had died within 2 years of completing the CWLS questionnaire ( $n=96$; data not shown). Furthermore, results were not materially different after additionally excluding women who $(a)$ reported unintentional weight loss of $>5 \%$ of their body weight in the year before completing the CWLS questionnaire $(n=265),(b)$ did not report having a mammogram or physician breast exam after their diagnosis $(n=148)$, and $(c)$ reported they were in poor health at the time of CWLS entry ( $n=41$; data not shown).

In additional analyses, we restricted analyses to postmenopausal women only $(n=3,757)$, and results were again similar to those reported in Table 3 (data not shown). Because of the small number of breast cancer deaths among premenopausal women with information on physical activity $(n=2)$, we could not evaluate the association among this subset of women.

Women in the highest categories of total recreational physical activity experienced consistently higher breast cancer survival compared with those in the lowest categories throughout follow-up (Fig. 1). The 5-year survival for breast cancer was $98 \%$ for women who engaged in $\geq 8.0 \mathrm{MET}-\mathrm{h} / \mathrm{wk}$ of recreational physical activity compared with $97 \%$ for $<2.8 \mathrm{MET}-\mathrm{h} / \mathrm{wk}$.

A similar inverse association between total recreational physical activity and risk of death from breast cancer was suggested among women with a younger and older age at diagnosis, women diagnosed with local and regional stage breast cancer, and normal-weight and overweight women (Table 4). In addition, we examined whether the influence of postdiagnosis physical activity on survival differs according to survival time; no significant effect modification by time since breast cancer diagnosis was observed $(P$ for interaction $=0.31$ ).

\section{Discussion}

The present data suggest that recreational physical activity after diagnosis of breast cancer may enhance 
survival in women with breast cancer. In our large cohort of breast cancer survivors for whom extensive information has been collected on postdiagnosis physical activity and other lifestyle-related variables, we found that women who engaged in $\geq 2.8 \mathrm{MET}-\mathrm{h} /$ wk of recreational physical activity had a $35 \%$ to $49 \%$ decreased risk of death from breast cancer compared with women who engaged in <2.8 MET-h/wk of activity; similar risk reductions were observed for all-cause mortality. Three MET-h is equivalent to walking at average pace of 2 to $2.9 \mathrm{mph}$ for $1 \mathrm{~h}$. The reduced risk of breast cancer death was limited to total or moderate-intensity physical activity; no benefit was noted for vigorous-intensity activity. Our data further suggest that the salutary influence of physical activity extends to women regardless of age at diagnosis (although in this study the majority of women were ages $>50$ years), stage of disease at diagnosis, and postdiagnosis BMI.

The broad distribution in survival times among women in the cohort allowed us to examine the influence of physical activity on survival in both early and late postdiagnostic periods. We examined whether the influence of physical activity on survival differs according to time since breast cancer diagnosis, and no statistically significant effect modification was observed. These results imply that physical activity has an important benefit on survival regardless of the interval since breast cancer diagnosis.

Physical activity has been associated with a decreased risk of breast cancer incidence in several studies (23), including the parent case-control study on which our follow-up study was based $(13,21)$. Inverse associations

Table 3. HR ( $95 \% \mathrm{Cl})$ for breast cancer and all-cause mortality according to total, moderate-intensity, or vigorousintensity recreational physical activity after breast cancer diagnosis in the CWLS

\begin{tabular}{|c|c|c|c|c|c|}
\hline & \multicolumn{4}{|c|}{ Total recreational physical activity after diagnosis (MET-h/wk) } & \multirow[t]{2}{*}{$P$ for linear trend } \\
\hline & $<2.8$ & $2.8-7.9$ & $8.0-20.9$ & $\geq 21.0$ & \\
\hline Breast cancer deaths & 37 & 26 & 25 & 21 & \\
\hline Multivariable HR $(95 \% \mathrm{CI})^{*}$ & 1.00 (Reference) & $0.62(0.37-1.03)$ & $0.53(0.31-0.88)$ & $0.44(0.25-0.76)$ & 0.01 \\
\hline Multivariable $\mathrm{HR}(95 \% \mathrm{CI})_{+}^{\dagger}$ & 1.00 (Reference) & $0.65(0.39-1.08)$ & $0.59(0.35-1.01)$ & $0.51(0.29-0.89)$ & 0.05 \\
\hline Multivariable $\mathrm{HR}(95 \% \mathrm{CI}){ }^{\ddagger}$ & 1.00 (Reference) & $0.66(0.39-1.13)$ & $0.61(0.36-1.05)$ & $0.49(0.27-0.89)$ & 0.05 \\
\hline Total deaths & 185 & 87 & 81 & 59 & \\
\hline Multivariable HR $(95 \% \mathrm{CI})^{*}$ & 1.00 (Reference) & $0.58(0.45-0.75)$ & $0.52(0.40-0.68)$ & $0.44(0.32-0.59)$ & $<0.001$ \\
\hline Multivariable HR $(95 \% \mathrm{CI})_{+}^{\dagger}$ & 1.00 (Reference) & $0.58(0.45-0.76)$ & $0.53(0.40-0.69)$ & $0.44(0.32-0.60)$ & $<0.001$ \\
\hline Multivariable HR $(95 \% \mathrm{CI}){ }^{\ddagger}$ & 1.00 (Reference) & $0.59(0.45-0.77)$ & $0.53(0.40-0.71)$ & $0.44(0.32-0.61)$ & $<0.001$ \\
\hline
\end{tabular}

Moderate-intensity ${ }^{\S}$ recreational physical activity after diagnosis (MET-h/wk) $P$ for linear trend

\begin{tabular}{|c|c|c|c|c|c|}
\hline & & \\
\hline & $<2.0$ & $2.0-3.9$ & $4.0-10.2$ & $\geq 10.3$ & \\
\hline Breast cancer deaths & 35 & 32 & 20 & 22 & \\
\hline Multivariable HR $(95 \% \mathrm{CI})^{*, \|}$ & 1.00 (Reference) & $0.69(0.43-1.12)$ & $0.47(0.27-0.83)$ & $0.41(0.24-0.73)$ & 0.01 \\
\hline Multivariable HR $(95 \% \mathrm{CI}){ }^{\dagger}, \|$ & 1.00 (Reference) & $0.71(0.44-1.16)$ & $0.49(0.28-0.88)$ & $0.47(0.26-0.83)$ & 0.03 \\
\hline Multivariable HR $(95 \% \mathrm{CI}){ }^{\ddagger}, \|$ & 1.00 (Reference) & $0.79(0.47-1.31)$ & $0.56(0.31-1.01)$ & $0.47(0.26-0.86)$ & 0.03 \\
\hline Total deaths & 161 & 117 & 72 & 62 & \\
\hline Multivariable HR $(95 \% \text { CI })_{+}^{*, \|}$ & 1.00 (Reference) & $0.67(0.53-0.85)$ & $0.63(0.47-0.84)$ & $0.47(0.35-0.64)$ & $<0.001$ \\
\hline Multivariable $\mathrm{HR}(95 \% \mathrm{CI})_{\dagger}^{\dagger}, \|$ & 1.00 (Reference) & $0.66(0.52-0.84)$ & $0.64(0.48-0.85)$ & $0.46(0.34-0.63)$ & $<0.001$ \\
\hline Multivariable HR $(95 \% \mathrm{CI})^{\ddagger}, \|$ & 1.00 (Reference) & $0.70(0.54-0.90)$ & $0.66(0.49-0.90)$ & $0.47(0.34-0.65)$ & $<0.001$ \\
\hline
\end{tabular}

Vigorous-intensity recreational physical activity after diagnosis (MET-h/wk) $P$ for linear trend

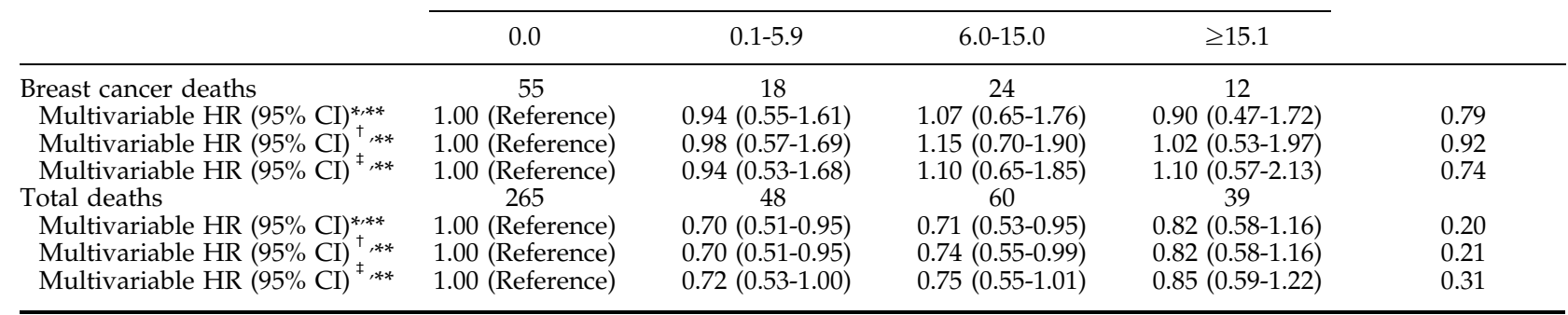

*Multivariable HR (95\% CI) adjusted for age at diagnosis, stage of disease at diagnosis, state of residence at diagnosis, and interval between diagnosis and physical activity assessment.

${ }^{\dagger}$ Additionally adjusted for postdiagnosis BMI, postdiagnosis menopausal status, postdiagnosis hormone therapy use, total energy intake year before enrollment in the CWLS, education level at diagnosis, family history of breast cancer at diagnosis, and initial treatment modality (radiation, chemotherapy, tamoxifen).

‡ Excludes 30 women who died within 1 year of returning the CWLS questionnaire, 7 of whom died from breast cancer.

\$oderate-intensity recreational physical activity include activities that expend <6.0 MET: walking outdoors and stair climbing.

$\|$ Additionally adjusted for vigorous-intensity recreational physical activity.

IVigorous-intensity recreational physical activity include activities that expend $\geq 6.0$ MET: running ( $\geq 10$ min/mile); calisthenics, aerobics, aerobic dance, and rowing machine; tennis, squash, or racquetball; lap swimming; and other aerobic recreation (e.g., lawn mowing).

**Additionally adjusted for moderate-intensity recreational physical activity. 


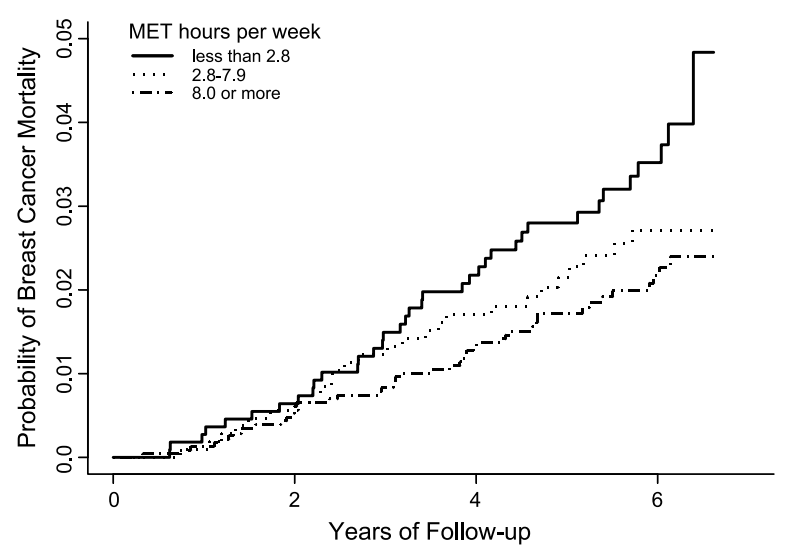

Figure 1. Cumulative incidence of breast cancer mortality by postdiagnosis total recreational physical activity category (MET-h/wk).

between prediagnostic recent (year before diagnosis) recreational physical activity and risk of breast cancer death have also been found $(24,25)$. However, few studies have examined postdiagnosis physical activity in relation to breast cancer survival. Consistent with the current results, a single prospective observational study among 2,987 female nurses diagnosed with breast cancer found that physical activity after diagnosis was associated with an inverse risk of breast cancer death (breast cancer deaths $=280$ ) and all-cause mortality (total deaths = 463; ref. 4). The multivariable relative risk of breast cancer death among women participating in $\geq 24$ MET$\mathrm{h} / \mathrm{wk}$ of total recreational physical activity was $0.60(95 \%$ CI, 0.40-0.89; $P$ for linear trend $=0.004$ ) compared with women who engaged in $<3$ MET-h/wk. The association with physical activity was particularly apparent among women who engaged in moderate-intensity physical activity (that is, walking) and among women with hormone-responsive tumors (4). Five ongoing prospective studies and two randomized control trials (reviewed in ref. 26) were specifically designed to address the relation between lifestyle factors, such as physical activity and diet, and breast cancer recurrence and survival are ongoing.

The strengths of our study include the prospective design, its large sample size, and detailed information available on recreational physical activity obtained after the diagnosis of breast cancer. In addition, we were able to assess a comprehensive list of potential confounders and effect modifiers in relation to physical activity and survival. In the current data, inverse associations with physical activity were not materially confounded by body weight. Furthermore, the inverse associations observed were consistent in both leaner and heavier women, suggesting that the apparent benefit is not mediated by effects of physical activity on body weight. Steroid receptor status was not available from state cancer registries for all CWLS participants; therefore, we could not evaluate this interaction in the current study.

The large size of the cohort, the broad geographic representation (the Midwest and rural and urban New England), and the wide spectrum in age provide assurance that results from this study are likely to be generalizable to a large number of woman with a diagnosis of breast cancer in the United States. However, our analysis was mainly among Caucasian women, so results may only apply to this subset of the population if the relationship between physical activity and survival varies according to ethnicity. Further studies will be needed to extend our results to other subgroups.

Table 4. Multivariable HR $(95 \% \mathrm{Cl})$ for breast cancer mortality according to total recreational physical activity category by selected characteristics in the CWLS

\begin{tabular}{|c|c|c|c|}
\hline & \multicolumn{2}{|c|}{ Total recreational physical activity after diagnosis (MET-h/wk)* } & \multirow[t]{2}{*}{$P$ for interaction } \\
\hline & $<8.0$ & $\geq 8.0$ & \\
\hline \multicolumn{4}{|l|}{ Age at diagnosis $\leq 59 \mathrm{y}$} \\
\hline Breast cancer deaths/total women & $35 / 917$ & $26 / 1,288$ & \\
\hline Multivariable HR $(95 \% \text { CI })^{\top}$ & 1.00 (Reference) & $0.53(0.31-0.89)$ & \\
\hline \multicolumn{4}{|l|}{ Age at diagnosis $>59$ y } \\
\hline Breast cancer deaths/total women & $28 / 1,260$ & $20 / 1,017$ & \\
\hline Multivariable HR $\left(95 \%\right.$ CI ${ }^{\dagger}$ & 1.00 (Reference) & $0.85(0.47-1.54)$ & 0.21 \\
\hline \multicolumn{4}{|l|}{ Local stage at diagnosis } \\
\hline Breast cancer deaths/total women & $24 / 1,610$ & $20 / 1,645$ & \\
\hline Multivariable HR $(95 \% \text { CI })^{\dagger}$ & 1.00 (Reference) & $0.81(0.44-1.51)$ & \\
\hline \multicolumn{4}{|l|}{ Regional stage at diagnosis } \\
\hline Breast cancer deaths/total women & $39 / 567$ & $26 / 660$ & \\
\hline Multivariable $\mathrm{HR}(95 \% \mathrm{CI})^{\dagger}$ & 1.00 (Reference) & $0.56(0.34-0.94)$ & 0.27 \\
\hline \multicolumn{4}{|l|}{ BMI $<25 \mathrm{~kg} / \mathrm{m}^{2}$} \\
\hline Breast cancer deaths/total women & $11 / 657$ & $15 / 1,051$ & \\
\hline Multivariable HR $(95 \% \text { CI })^{\dagger}$ & 1.00 (Reference) & $0.91(0.39-2.13)$ & \\
\hline \multicolumn{4}{|l|}{ BMI $\geq 25 \mathrm{~kg} / \mathrm{m}$} \\
\hline Breast cancer deaths/total women & $47 / 1,372$ & $28 / 1,157$ & \\
\hline Multivariable HR $(95 \% \mathrm{CI})^{\dagger}$ & 1.00 (Reference) & $0.63(0.39-1.02)$ & 0.59 \\
\hline
\end{tabular}


We used a validated self-reported measure of recreational physical activity adapted from the Nurses' Health Study. Some measurement error is likely to be present in the physical activity measure as we, similar to the Nurses' Health Study, only assessed self-reported leisure-time activity. Limitations include the lack of information on occupational and normal activity levels, including housework. However, as most of these women were nearing or at retirement age, we expect that the resulting misclassification, if any, would have been minimal. Furthermore, associations with this measure of physical activity and cancer incidence in the Nurses' Health Study have been consistent in the literature. For example, physical activity is inversely associated with cancers of the breast (27), colon (28), and pancreas (29) as well as coronary heart disease (30), stroke (31), and type 2 diabetes (32).

This suggests that our measure of physical activity is sufficiently accurate to detect important disease relationships. Information on prediagnostic physical activity available from interviews obtained in the parent casecontrol study varied in detail and included activities in adolescence and young adulthood, to within 5 years of breast cancer diagnosis, to an entire lifetime (see Materials and Methods); therefore, not all women had available data for the different measures of prediagnostic physical activity. We were unable to assess, for some women, recent (year before diagnosis) or lifetime total recreational physical activity, which may be the more ideal measures of prediagnostic physical activity. It is unclear when during the lifespan physical activity would have the greatest effect on surviving breast cancer; therefore, the ability to assess physical activity using several different periods before diagnosis in at least some subjects may be considered a strength of the current study.

The CWLS was initiated in women that were previously enrolled in a case-control study of breast cancer. A proportion of women eligible did not participate in the CWLS; nonparticipants were more likely to have regional involvement of their breast cancer, smoke at the time of diagnosis, and have less education. A potential concern is that selective nonresponse (mainly by either refusal or death) may in part explain the inverse associations observed. Although we attempted to minimize nonparticipation in the recruitment of participants, we are unable to rule out such bias in the data, and findings may not be generalizable to all women with a breast cancer diagnosis. Because women were not followed from the initial diagnosis of their breast cancer, one practical limitation of the data is that our results may only be applicable to women who survive the first several years after breast cancer diagnosis.

An additional concern is that the inverse associations with mortality observed in these data might reflect "reverse causation" if reduced physical activity is associated with worsening health and a poor prognosis is related to the breast cancer. Although it is not possible to rule out such bias in the data, the analyses overall suggest that it does not explain entirely the inverse associations we observed with physical activity. The relatively short interval between diagnosis and subsequent entry into the cohort for the majority of women minimizes the likelihood of bias caused by selective survival. Furthermore, we showed that all associations were essentially unchanged after breast cancer stage and other prognostic factors were included in statistical models and in analyses restricted to women that had survived a minimum of 1 and 2 years after completing the CWLS questionnaire and who were in apparent good health at the time of CWLS entry. Risk estimates reported here are consistent with another prospective cohort study that reported an apparent inverse association between postdiagnosis physical activity and breast cancer survival and overall longevity (4).

This study provides additional support for a beneficial relation between physical activity after a breast cancer diagnosis and survival. Given the consistencies already evident in the literature, findings from ongoing prospective cohort studies and randomized control trials in breast cancer survivors will be important in providing evidence on how to improve longevity after a breast cancer diagnosis. Until more information is available from these studies, it may well be a benefit for women with breast cancer to follow guidelines provided by the American Cancer Society (33) recommending at least 30 min of moderate physical activity at least 5 days a week to maintain a healthy lifestyle.

\section{References}

1. Ries L, Harkins D, Krapcho M. Surveillance, Epidemiology, and End Results (SEER) cancer statistics review, 1975-2003. Bethesda (MD): National Cancer Institute; 2006.

2. Schemper $\mathrm{M}$. The relative importance of prognostic factors in studies of survival. Stat Med 1993;12:2377-82.

3. Mutrie N, Campbell AM, Whyte F, et al. Benefits of supervised group exercise programme for women being treated for early stage breast cancer: pragmatic randomised controlled trial. BMJ 2007;334:517

4. Holmes MD, Chen WY, Feskanich D, Kroenke CH, Colditz GA. Physical activity and survival after breast cancer diagnosis. JAMA 2005;293:2479-86.

5. Holmberg L, Norden T, Lindgren A, Wide L, Degerman M, Adami HO. Pre-operative oestradiol levels-relation to survival in breast cancer. Eur J Surg Oncol 2001;27:152-6.

6. Lonning PE, Helle SI, Johannessen DC, Ekse D, Adlercreutz H. Influence of plasma estrogen levels on the length of the disease-free interval in postmenopausal women with breast cancer. Breast Cancer Res Treat 1996;39:335-41.

7. Goodwin PJ, Ennis M, Pritchard KI, et al. Fasting insulin and outcome in early-stage breast cancer: results of a prospective cohort study. J Clin Oncol 2002;20:42-51.

8. Irwin ML, McTiernan A, Bernstein L, et al. Relationship of obesity and physical activity with C-peptide, leptin, and insulin-like growth factors in breast cancer survivors. Cancer Epidemiol Biomarkers Prev 2005; $14: 2881-8$.

9. Kroenke $\mathrm{CH}, \mathrm{Chen} \mathrm{WY}$, Rosner B, Holmes MD. Weight, weight gain, and survival after breast cancer diagnosis. J Clin Oncol 2005;23:1370-8.

10. Jemal A, Siegel R, Ward E, Murray T, Xu J, Thun MJ. Cancer statistics, 2007. CA Cancer J Clin 2007;57:43-66.

11. Newcomb PA, Storer BE, Longnecker MP, et al. Lactation and a reduced risk of premenopausal breast cancer. N Engl J Med 1994;330: $81-7$.

12. Titus-Ernstoff L, Longnecker MP, Newcomb PA, et al. Menstrual factors in relation to breast cancer risk. Cancer Epidemiol Biomarkers Prev 1998;7:783-9.

13. Sprague BL, Trentham-Dietz A, Newcomb PA, Titus-Ernstoff L, Hampton JM, Egan KM. Lifetime recreational and occupational physical activity and risk of in situ and invasive breast cancer. Cancer Epidemiol Biomarkers Prev 2007;16:236-43.

14. Thoburn KK, German RR, Lewis M, Nichols PJ, Ahmed F, JacksonThompson J. Case completeness and data accuracy in the Centers for Disease Control and Prevention's National Program of Cancer Registries. Cancer 2007;109:1607-16.

15. Titus-Ernstoff L, Egan KM, Newcomb PA, et al. Exposure to breast milk in infancy and adult breast cancer risk. J Natl Cancer Inst 1998; 90:921-4.

16. Wolf AM, Hunter DJ, Colditz GA, et al. Reproducibility and validity of a self-administered physical activity questionnaire. Int J Epidemiol $1994 ; 23: 991-9$. 
17. Ainsworth BE, Haskell WL, Leon AS, et al. Compendium of physical activities: classification of energy costs of human physical activities. Med Sci Sports Exerc 1993;25:71-80.

18. Pate RR, Pratt M, Blair SN, et al. Physical activity and public health. A recommendation from the Centers for Disease Control and Prevention and the American College of Sports Medicine. JAMA 1995;273:402-7.

19. Calle EE, Terrell DD. Utility of the National Death Index for ascertainment of mortality among cancer prevention study II participants. Am J Epidemiol 1993;137:235-41.

20. Stampfer MJ, Willett WC, Speizer FE, et al. Test of the National Death Index. Am J Epidemiol 1984;119:837-9.

21. Mittendorf R, Longnecker MP, Newcomb PA, et al. Strenuous physical activity in young adulthood and risk of breast cancer (United States). Cancer Causes Control 1995;6:347-53.

22. Mantel N. Evaluation of survival data and two new rank order statistics arising in its consideration. Cancer Chemother Rep 1966;50:163-70.

23. Bianchini F, Kaaks R, Vainio H. Weight control and physical activity in cancer prevention. Obes Rev 2002;3:5-8.

24. Abrahamson PE, Gammon MD, Lund MJ, et al. Recreational physical activity and survival among young women with breast cancer. Cancer 2006;107:1777-85.

25. Enger SM, Bernstein L. Exercise activity, body size and premenopausal breast cancer survival. Br J Cancer 2004;90:2138-41.
26. Kushi LH, Kwan ML, Lee MM, Ambrosone CB. Lifestyle factors and survival in women with breast cancer. J Nutr 2007;137: $236-42 S$.

27. Rockhill B, Willett WC, Hunter DJ, Manson JE, Hankinson SE, Colditz GA. A prospective study of recreational physical activity and breast cancer risk. Arch Intern Med 1999;159:2290-6.

28. Martinez ME, Giovannucci E, Spiegelman D, Hunter DJ, Willett WC, Colditz GA; Nurses' Health Study Research Group. Leisure-time physical activity, body size, and colon cancer in women. J Natl Cancer Inst 1997;89:948-55.

29. Michaud DS, Giovannucci E, Willett WC, Colditz GA, Stampfer MJ, Fuchs CS. Physical activity, obesity, height, and the risk of pancreatic cancer. JAMA 2001;286:921-9.

30. Manson JE, Hu FB, Rich-Edwards JW, et al. A prospective study of walking as compared with vigorous exercise in the prevention of coronary heart disease in women. N Engl J Med 1999;341:650-8.

31. Hu FB, Stampfer MJ, Colditz GA, et al. Physical activity and risk of stroke in women. JAMA 2000;283:2961-7.

32. Hu FB, Sigal RJ, Rich-Edwards JW, et al. Walking compared with vigorous physical activity and risk of type 2 diabetes in women: a prospective study. JAMA 1999;282:1433-9.

33. Brown JK, Byers T, Doyle C, et al. Nutrition and physical activity during and after cancer treatment: an American Cancer Society guide for informed choices. CA Cancer J Clin 2003;53:268-91. 


\section{Cancer Epidemiology, \\ Biomarkers \& Prevention}

\section{Physical Activity and Survival after Diagnosis of Invasive Breast Cancer}

Crystal N. Holick, Polly A. Newcomb, Amy Trentham-Dietz, et al.

Cancer Epidemiol Biomarkers Prev 2008;17:379-386.

Updated version Access the most recent version of this article at:

http://cebp.aacrjournals.org/content/17/2/379

Cited articles This article cites 32 articles, 6 of which you can access for free at:

http://cebp.aacrjournals.org/content/17/2/379.full\#ref-list-1

Citing articles This article has been cited by 32 HighWire-hosted articles. Access the articles at:

http://cebp.aacrjournals.org/content/17/2/379.full\#related-urls

E-mail alerts Sign up to receive free email-alerts related to this article or journal.

Reprints and To order reprints of this article or to subscribe to the journal, contact the AACR Publications

Subscriptions Department at pubs@aacr.org.

Permissions To request permission to re-use all or part of this article, use this link http://cebp.aacrjournals.org/content/17/2/379.

Click on "Request Permissions" which will take you to the Copyright Clearance Center's (CCC)

Rightslink site. 